\title{
RESENHA
}

\section{Senadores do presidencialismo de coalizão brasileiro}

Theófilo Codeco Machado Rodrigues ${ }^{1}$

Como citar esta resenha: RODRIGUES, Theófilo Codeco Machado. Senadores do presidencialismo de coalizão brasileiro. Revista de Ciências do Estado. Belo Horizonte: v. 5, n. 1, e16377. ISSN: 2525-8036.

Resenha de PAULA, Carolina de. O que faz um Senador? Um estudo sobre a representação política dos senadores brasileiros. Curitiba: Appris, 2018.

Recebido em 16.01.2020

Aprovado em 06.05.2020

Publicado em 20.05.2020

Por diversas razões ainda pouco explicadas, o Senado brasileiro nunca foi um objeto privilegiado de pesquisa para a literatura especializada como foi a Câmara dos Deputados. Curioso que seja assim. Como sabemos, o Senado reúne a elite da política brasileira, entre presidentes de partido, ex-governadores e até ex-presidentes. Diga-se de passagem, dentre os seis presidentes da Nova República, entre 1985 e 2018, três assumiram posteriormente uma cadeira no Senado - José Sarney, Fernando Collor e Itamar Franco - além de Dilma Rousseff que tentou uma vaga, mas foi derrotada na eleição de 2018. Trata-se, portanto, de um mistério pouco explicável que uma arena política como essa receba ainda pouca atenção dos pesquisadores.

Sob esse registro, merece destaque a recente publicação do livro "O que faz um Senador? Um estudo sobre a representação política dos senadores brasileiros" de Carolina de Paula. Trata-se da tese de doutorado da cientista política, defendida em 2014, no IESP-UERJ, sob a orientação de Jairo Nicolau, mas que se tornou livro, em 2018, pela editora Appris. Com a linguagem de quem está acostumada em trabalhar com comunicação política, o livro possui uma fácil leitura, não obstante a vasta quantidade de informações reunidas pela autora. O livro

\footnotetext{
1 Theófilo Codeço Machado Rodrigues é Doutor em Ciências Sociais pela PUC-Rio e Mestre em Ciência Política pela UFF. Atualmente realiza Pós-Doutorado no Programa de Pós-Graduação em Ciências Sociais da UERJ.
} 
está subdividido em cinco capítulos: os dois primeiros trazem um recorte teórico; os três seguintes apresentam os resultados da pesquisa empírica empreendida pela autora.

Logo de início, na introdução e no primeiro capítulo, Carolina de Paula já nos esclarece que a escassez de trabalhos sobre o Senado não é exclusividade da ciência política brasileira. De forma contra intuitiva, o mesmo ocorre nos Estados Unidos, território fértil para pesquisas sobre instituições política em geral e sobre o legislativo, em particular. Essa escassez, claro, não significa uma total ausência. Há trabalhos de qualidade sobre o Senado no Brasil, em particular após o fim da década de 90, e a autora traz ao leitor uma boa organização desse estado da arte. Essa literatura é categorizada por Carolina de Paula (2018, p. 17) de três modos: (1) pesquisas que identificam a força/fraqueza do Senado em relação ao regime presidencial (BACKES, 1998; NEIVA, 2004 e 2008; ANASTASIA, MELO e SANTOS, 2004; BRANCO, 2007); (2) estudos sobre o processo legislativo e questões organizacionais do Senado (DESPOSATO, 2006; ARAÚJO, 2008 e 2009; RICCI, 2008; LEMOS, 2008; NEIVA, 2011; ARRETCHE, 2013; NEIVA e SOARES, 2013); (3) e sobre o perfil dos senadores (BOHN, 2008; LLÁNOS e SÁNCHEZ, 2008; SILVA, 2010; COSTA, 2010; NEIVA e IZUMI, 2012; COSTA e CODATO, 2013). Aqui encontramos um ponto forte da sistematização do estado da arte. Sabe-se que na literatura acadêmica internacional o trabalho de Alfred Stepan (1999) ocupa um locus de destaque nos estudos sobre as relações entre Executivo e Legislativo. Em síntese, seu argumento contra o bicameralismo é o de que o Senado possui um nítido perfil antidemocrático na medida em que "algumas federações, tais como a do Brasil, que adotam o perfil igualitário de membros do Congresso, distorcem as decisões tomadas na 'legítima' Casa da maioria, a Câmara Baixa” (PAULA, 2018, p. 33). Em outras palavras, o Senado desvirtuaria a "verdadeira" representação da população que seria garantida pela Câmara de Deputados. Conforme Carolina de Paula nos sugere, a literatura nacional sobre o Senado refuta a tese de Stepan ao demonstrar que "as diversas reformas constitucionais aprovadas pelo Executivo nas décadas de 1990 e 2010 são exemplos de que a paridade de senadores em cada estado não suscita a tirania da minoria" (PAULA, 2018, p. $38)$.

O segundo capítulo resgata o debate clássico e contemporâneo da teoria sobre a representação política para a melhor compreensão do formato do sistema político brasileiro. Com desenvoltura analítica a autora percorre desde clássicos como John Stuart Mill e os federalistas Hamilton, Madison e Jay até contemporâneos como Hanna Pitkin e Bernard Manin. Embora a autora não desenvolva a conexão, há um importante ponto de encontro entre o argumento desenvolvido pelos federalistas e a tese de Stepan. Grosso modo, Hamilton, 
Madison e Jay estão entre os muitos fundadores do governo representativo como conhecemos, ou seja, com a separação das funções do poder entre Executivo, Legislativo e Judiciário. O argumento central desenvolvido pelos autores é o de que somente o poder pode fiscalizar o poder, o que a teoria política convencionou chamar de sistema de freios e contrapesos ou checks and balances. Mas essa engenharia institucional não deveria existir apenas entre os três poderes, mas também internamente, em particular no Legislativo. Esse é o tema do famoso artigo 51 de $O$ Federalista, bem explorado pela autora (PAULA, 2018, p. 59). Na medida em que o Legislativo seria o poder mais forte, já que derivado diretamente do povo, só haveria uma forma de impedir uma possível "tirania da maioria": a divisão desse Legislativo em duas casas. Note-se aqui o velho temor liberal da "tirania da maioria". A criação do Senado serviria a esse interesse. Ora, em outros termos, é exatamente essa a denúncia de Stepan sobre a distorção democrática.

Esse debate teórico sobre a representação política é o alicerce para a autora observar de forma original as características do sistema político brasileiro. Em primeiro lugar, os efeitos do sistema eleitoral majoritário para o Senado são interessantes. Desde Duverger a literatura convencionou considerar que sistemas eleitorais majoritários de um único turno reduziriam a quantidade de partidos políticos em determinados sistemas. De fato, há menos partidos políticos representados no Senado do que na Câmara. Mas, ainda assim, o número de partidos presentes no Senado é alto. Em segundo lugar, a literatura especializada afirma que o sistema eleitoral influi na participação de gênero no Legislativo. Em teoria, sistemas proporcionais de voto seriam mais aptos para a simetria de gênero do que os majoritários. Entretanto, ao cotejar os dados das duas casas a autora percebeu que no caso brasileiro as mulheres encontram no Senado mais sucesso do que na Câmara. Sua conclusão é a de que não é exatamente o voto proporcional o mais relevante, mas sim se ele é de lista aberta ou fechada (PAULA, 2018, p. 68). Ou seja, o voto proporcional de lista aberta, como no Brasil, é menos favorável à participação das mulheres do que o voto proporcional de lista fechada, como na Argentina. Os efeitos do bicameralismo sobre a representação política também são avaliados. Assim como argumentavam os federalistas, a autora observa que o modelo bicameral brasileiro contribui para a "prevenção da tirania da maioria" (PAULA, 2018, p. 72) e para a “preservação da representação das minorias no país” (PAULA, 2018, p. 74).

Com o terceiro capítulo tem início a apresentação dos dados mais empíricos levantados pela autora. Especificamente neste capítulo está presente, com maior ênfase, um tema que é uma especialidade de Carolina de Paula: a comunicação política. Mais 
precisamente, o foco é na campanha desenvolvida no Horário Gratuito de Propaganda Eleitoral (HGPE) pelos quatro principais candidatos à vaga de Senador no Rio de Janeiro em 2010: Lindbergh Farias do PT, Marcelo Crivella do PRB, Jorge Picciani do PMDB e Cesar Maia do DEM. Ao todo foram analisados 19 programas de cada um dos quatro candidatos, totalizando 76 programas. Ao segmentar a narrativa dos candidatos em diversas categorias, a autora traz achados interessantes. Os candidatos vitoriosos - Lindbergh e Crivella - possuem em comum o fato de não terem focado seus discursos em prefeitos, municípios específicos, segmentos religiosos ou em militantes partidários, mas sim no eleitor individualmente (PAULA, 2018, p. 95). Essa parece ser a estratégia mais acertada em uma eleição majoritária. Os dois também apostaram em criar uma narrativa semelhante sobre o que consideravam ser as principais atividades de um senador, quais sejam, o diálogo com o Executivo federal e a captação de recursos para o estado (PAULA, 2018, p. 97). Claro, essa narrativa faz sentido quando analisado o contexto. Os dois eleitos faziam parte da base do governo federal que contava, naquele momento, com altos índices de aprovação. Uma hipótese intuitiva seria a de que uma pesquisa feita em outro contexto, de baixa aprovação do governo federal, talvez revelasse que narrativas diferentes, como a fiscalização do Poder Executivo, fossem preferíveis. Aos interessados no tema, neste capítulo encontramos uma das mais completas sistematizações do estado da arte dos estudos de HGPE.

Após a observação do HGPE feita no terceiro capítulo, o quarto capítulo avalia a própria opinião dos senadores. Para tanto, a autora recolheu os dados obtidos pela Pesquisa Legislativa Brasileira coordenada por Timothy Power e Cesar Zucco Jr. Essa pesquisa reuniu as opiniões de 27 senadores no ano de 2009. Os resultados são reveladores. Quando questionados se o mais importante para suas vitórias eleitorais seria o partido os seus esforços pessoais, praticamente todos os senadores pesquisados disseram o mesmo: os esforços pessoais. Quando segmentamos essa opinião por partido o dado torna-se ainda mais revelador. Os senadores do PMDB tendem a considerar o partido mais importante do que os senadores do PT (PAULA, 2018, p. 117). Esse achado é contra intuitivo, já que a literatura costuma definir o PT como a estrutura partidária formadora de laços de identidade mais forte do Brasil. Esse dado, no entanto, inverte-se quando os senadores são perguntados sobre como agiriam numa situação de conflito entre os interesses locais e as posições partidárias. Todos os senadores do PMDB ouvidos afirmam que ficariam com os interesses locais, enquanto aproximadamente metade dos senadores petistas preferem mediar o conflito e dividir o voto entre os interesses locais e os partidários. Ou seja, a importância da estrutura partidária do PT apontada pela literatura é confirmada (PAULA, 2018, p. 133). 
Se a ênfase do quarto capítulo esteve no viés quantitativo, no quinto e último capítulo a autora inovou e aprofundou uma pesquisa qualitativa. Trata-se de um ponto forte do livro. A ciência política, em geral, busca trabalhar com dados mais quantitativos, enquanto a pesquisa qualitativa costuma ser preferida pela antropologia política. Ter a habilidade de reunir, em um mesmo trabalho, os dois métodos, certamente enriqueceu a pesquisa de Carolina de Paula. Interessante, inclusive, como a autora apresenta os dados como em um diário de campo de uma antropóloga, com seus obstáculos, suas dificuldades, e suas alternativas para contornar os dilemas que surgem em pesquisas desse feitio. Ao todo, a autora conseguiu realizar entrevistas de profundidade com cinco senadores: Eduardo Suplicy, do PT de São Paulo; Humberto Costa, do PT de Pernambuco; Aníbal Diniz, do PT do Acre; Cassildo Maldaner, do PMDB de Santa Catarina; e Sergio Souza do PMDB do Paraná. Apesar da diversidade regional, talvez tenha faltado uma maior pluralidade partidária dentre os entrevistados, o que enriqueceria ainda mais a pesquisa. Entre os muitos insights que as entrevistas suscitam, dois me parecem os mais relevantes por dialogarem diretamente com as intuições da ciência política: a conexão entre as campanhas de senador e governador; e o papel que a vaga de suplente ocupa nas articulações político-partidárias (PAULA, 2018, p. 175-176).

Uma pena que o trabalho tenha sido concluído antes das eleições de 2018. Certamente, este foi um ano em que, mais do que nunca, a eleição para o Senado operou com surpresas. Presidentes dos principais partidos políticos brasileiros, os senadores Aécio Neves do PSDB e Gleisi Hoffmann do PT, optaram por não disputar a reeleição no Senado e seguiram, em voo mais baixo, para a Câmara dos Deputados. Presidente do MDB, o senador Romero Jucá tentou a reeleição, mas foi derrotado. Ao mesmo tempo, figuras ilustres como a ex-presidente Dilma Rousseff, e os ex-senadores Lindbergh Farias, Eduardo Suplicy, Eunício de Oliveira e Roberto Requião não conquistaram vagas na Câmara Alta. Com novos atores, essa arena da luta política mantém-se como objeto privilegiado de pesquisa, como bem destaca o livro de Carolina de Paula.

\section{REFERÊNCIAS BIBLIOGRÁFICAS}

ANASTASIA, Fátima; MELO, Carlos Ranulfo; SANTOS, Fabiano. Governabilidade e representação política na América do Sul. Rio de Janeiro: Fundação Konrad Adenauer, 2004.
ARAÚJO, Paulo. "A câmara alta no Legislativo brasileiro: o desempenho legislativo do Senado entre 1989 e 2000", in Leany Lemos (org.), O Senado federal brasileiro no pós-Constituinte. Brasília, 
Editora do Senado Federal, pp. 203-236, 2008.

O bicameralismo no Brasil: as bases institucionais e políticas do desempenho legislativo do Senado federal (19892004). 279f. 2009. Tese (Doutorado em Ciência Política) - Faculdade de Filosofia e Ciências Humanas, Universidade Federal de Minas Gerais, Belo Horizonte, 2009.

ARRETCHE, Marta. Demos-constraining or Demos-enabling federalismo? Political institutions and policy change in Brazil. Journal of politics in Latin America, v. 5, 2013.

BACKES, Ana Luíza. Democracia e sobre-representação de regiões: o papel do Senado. 149f. 1998. Dissertação (Mestrado em Ciência Política) Universidade de Brasília, Brasília, 1998.

BOHN, Simone. Mulheres e qualidade das candidaturas nas eleições para o Senado: Brasil e estados em contraste. In: LEMOS, Leany (org.), O Senado federal brasileiro no pós-Constituinte. Brasília, Editora do Senado Federal, 2008. BRANCO, Marcello. A democracia federativa brasileira e o papel do Senado no ajuste fiscal dos anos 90. 215f. 2007. Tese (Doutorado em Ciência Política) Faculdade de Filosofia e Ciências Humanas, Universidade Federal de Minas Gerais, Belo Horizonte, 2009.

COSTA, Luiz. Composição social e carreira política dos senadores brasileiros (1986-2006). 118f. 2010. Dissertação (Mestrado em Ciência Política) - Instituto de Filosofia e Ciências Humanas, Universidade Estadual de Campinas, Campinas, 2010.
CODATO, Adriano. A profissionalização ou popularização da classe política: um perfil dos senadores da república. In: MARENCO DOS SANTOS, André (org). Os eleitos: representação e carreiras políticas em democracias. 1ed. Porto Alegre: UFRGS, 2013.

DESPOSATO, Scott. The impact os electoral rules on legislative parties: lessons from the brazilian Senate and Chamber os Deputies. The Jounal os politics, v 68, n 4, p. 1.015-1027, 2006.

LEMOS, Leany (org.), O Senado federal brasileiro no pós-Constituinte. Brasília: Editora do Senado Federal, 2008.

LLANOS, Mariana; SÁNCHEZ, Francisco. Conselho de anciãos? O Senado e seus parlamentares no Cone Sul. In: LEMOS, Leany (org.), O Senado federal brasileiro no pós-Constituinte. Brasília, Editora do Senado Federal, 2008. NEIVA, Pedro. Estudos comparado de Câmaras altas: os pderes e o papel dos senados nos sistemas presidencialistas. 278f. 2004. Tese (Doutorado em Ciência Política) - Instituto Universitário de Pesquisas do Rio de Janeiro, Rio de Janeiro, 2004.

Os poderes dos Senados de países presidencialistas e o caso do Brasil. In: LEMOS, Leany (Org.) O Senado federal brasileiro no pós-Constituinte. Brasília: Senado Federal, Unilegis, 2008.

"Coesão e disciplina partidária no Senado Federal". Dados, 54 (2): 289-318, 2011.

IZUMI, Maurício. "Os sem-votos do Legislativo brasileiro: quem são os 
senadores suplentes e quais os seus impactos sobre o processo legislativo". Opinião Pública, 18 (1): 1-21, 2012.

SOARES, Márcia Miranda. Senado brasileiro: casa federativa ou partidária?. Rev. bras. Ci. Soc., São Paulo, v. 28, n. 81, p. 97-115, fev. 2013.

PAULA, Carolina de. O que faz um Senador? Um estudo sobre a representação política dos senadores brasileiros. Curitiba: Appris, 2018.

RICCI, Paolo. "A produção legislativa de iniciativa parlamentar no Congresso brasileiro: diferenças e similaridades entre a Câmara dos Deputados e o
Senado federal". In: LEMOS, Leany (org.), O Senado federal brasileiro no pósConstituinte. Brasília, Editora do Senado Federal, pp. 237-271, 2008.

SILVA, Rodrigo. Senado: casa dos senhores? Os perfis de carreira dos senadores eleitos entre 1990 e 2006. 133f. 2010. Dissertação (Mestrado em Ciência Política) - Instituto de Filosofia e Ciências Humanas, Universidade Federal do Rio Grande do Sul, Porto Alegre, 2010.

STEPAN, Alfred. Para uma nova análise comparativa do federalismo e da democracia: federações que restringem ou ampliam o poder do Demos. Dados, Rio de Janeiro, v. 42, n. 2, 1999.

\section{SENATORS OF BRAZILIAN COALITION PRESIDENTIALISM}

Theófilo Codeco Machado Rodrigues

How to cite this article: RODRIGUES, Theófilo Codeco Machado. Senadores do presidencialismo de coalizão brasileiro. Revista de Ciências do Estado. Belo Horizonte: v. 5, n. 1, e16377. ISSN: 2525-8036. 